\title{
Derecho a la educación y autonomía zapatista en Chiapas, México
}

\author{
Right to education and zapatista autonomy in Mexico
}

\author{
Bruno Baronnet / bruno.baronnet@gmail.com \\ Universidad Veracruzana, México
}

\begin{abstract}
Some political practices of indigenous education in the jungle valleys of Ocosingo in Chiapas are analyzed here from a sociological approach. The Zapatista experience of autonomy demonstrates a profound questioning of the educational policies of the nationstate. Education projects in indigenous peoples from Zapatista municipalities challenge the institutionalized practices of the dominant actors in this field in Mexico and in the Latin American context as one of the struggles of indigenous peoples to change the norms of educational policy. Furthermore, the Zapatista experience in the region of recovered land from the Lacandon Jungle questions the limitations of the national project of theories and practices inherited from the Mexican indigenismo. Today, those are immersed in the discourses of neoliberal multiculturalism that tend to avoid the social issue of political autonomy.
\end{abstract}

Key words: intercultural education, multiculturalism, indigenous people, EZLN, zapatismo.

Resumen: Distintas prácticas políticas de educación de los pueblos indígenas de Las Cañadas de Ocosingo, en Chiapas, están analizadas aquí a partir de un enfoque sociológico. La experiencia zapatista de autonomía aporta una demostración del cuestionamiento profundo de la política de educación del Estado nación. Los proyectos de educación de los pueblos indígenas que pertenecen a los municipios zapatistas desafían las prácticas institucionalizadas de los actores dominantes en este campo en México, y en el contexto latinoamericano de las luchas de los pueblos originarios para cambiar la normatividad de las políticas educativas. Además, la experiencia zapatista en la región de las tierras recuperadas de la Selva Lacandona pone en tela de juicio las limitaciones del proyecto nacional heredado de teorías y prácticas del indigenismo mexicano que hoy están inmersas en los discursos del multiculturalismo neoliberal, en los cuales se elude la cuestión social de la autonomía política.

Palabras clave: educación intercultural, multiculturalismo, pueblos indígenas, EZLN, zapatismo. 


\section{Introducción}

Los servicios de educación básica en los pueblos originarios de la Selva Lacandona de Chiapas son redefinidos por el surgimiento de la demanda social de autonomía política que se ha vuelto realidad en las prácticas cotidianas. Desde hace una década y media, en Las Cañadas de Ocosingo varios cientos de comunidades campesinas, en su mayoría tseltales, están construyendo alternativas escolares fuera de la política gubernamental que llaman "oficial". Frente al Estado nación, la construcción social de la autonomía educativa forma parte de proyectos endógenos amplios de profundización de las prácticas de autogobierno regional. En estos territorios de influencia zapatista, los actores educativos que hablan tseltal en sus hogares, pero también ch'ol, tojolab'al y tsotsil, utilizan las variantes de las lenguas originarias mayas y la "castilla", tanto en la comunicación política como en sus modestas aulas, clínicas, milpas y cooperativas de producción. ¿Cómo el derecho a la educación se configura en las prácticas autonómicas de los pueblos indígenas? ¿Qué significados adquieren éstas en términos de cambios sociopolíticos?

La lucha por la autonomía educativa de los pueblos indígenas aparece como un aspecto primordial en las estrategias sociales de defensa del territorio, la afirmación cultural y el fortalecimiento de las capacidades de gestión local de las familias implicadas. Así, en muchos de los recientes asentamientos indígenas en los valles de la Selva Lacandona se desarrollan novedosas experiencias comunitarias y regionales de construcción social de discursos y prácticas políticas de educación básica. Más allá de considerar estas prácticas autonómicas como "ilegales" desde el punto de vista del Estado, el ejercicio del derecho de los pueblos originarios a la autodeterminación en sus propios asuntos educativos muestra la realidad de una participación social, nada "ilegítima”, en la construcción de proyectos escolares municipales, creativos y en rebelión ante las políticas nacionales. ¿En qué sentido representan un desafío social relevante?

Incluso en contextos y circunstancias difíciles, el proyecto radical de autonomía indígena se erige en Las Cañadas de Ocosingo aportando un marco intercomunitario democrático, que permite una lenta consolidación de formas alternativas de organización de la escuela. Esto lleva a considerar a la educación autónoma a partir de las prácticas políticas y pedagógicas de la población indígena y campesina que la sostiene con sus propios recursos materiales, relacionales y organizativos (Baronnet, 2012). De acuerdo con observaciones etnográficas propias (2005-2011) y un análisis socioantropológico multidimensional, se establece que estos proyectos políticos de edu- 
cación primaria muestran un cuestionamiento a la práctica centralizadora del sistema educativo de corte neoindigenista, pero dependen mucho de la participación colectiva.

Este artículo empieza por presentar la cuestión social de la política de la autonomía y el derecho a una educación propia en el caso de una región zapatista del Sureste mexicano. En un segundo momento, dicha experiencia chiapaneca está contextualizada y puesta en perspectiva desde el marco de las luchas indígenas de Latinoamérica por la autonomía educativa a nivel regional. Luego, se aportan consideraciones específicas acerca del significado de la experiencia zapatista a la luz de su cuestionamiento crucial a las políticas nacionales de educación indígena e intercultural. Antes de concluir sobre el sentido que cobran las prácticas de lucha por la dignidad en la educación, se analizan los efectos de la autonomía en la escuela como derivaciones de una apuesta política y participativa que está dirigida a descolonizar la cultura escolar discriminante. Muchas de las prácticas autonómicas observables en el zapatismo reciben asimismo la influencia de las culturas y lenguas mayas en el ejercicio de facto de los derechos educativos.

\section{Política de la autonomía y derecho a una educación propia}

Desde hace cerca de 15 años, la conjunción de diversos procesos políticos y estrategias socioétnicas ha permitido la emergencia de redes educativas autogestionadas por pueblos indígenas organizados entre sí. El cambio radical de política educativa que impulsan los municipios autónomos rebeldes zapatistas (MAREZ) desemboca en la toma de control de la gestión administrativa y pedagógica de las escuelas por las familias que ocupan decenas de miles de hectáreas de tierras tomadas el 1 de enero de 1994.

A partir de sus propias reglas y recursos, las bases de apoyo del Ejército Zapatista de Liberación Nacional (EZLN) definen los contornos y los contenidos de políticas locales de educación propia que no responden a los dictados por la Secretaría de Educación Pública (SEP). Así, la demanda de autonomía en la educación básica está alimentada por el movimiento social y cultural de comunidades campesinas en una zona del conflicto armado (hostigamientos, ocupación militar y paramilitarismo) donde, según el censo del año 2000 , el analfabetismo afecta a cerca del $40 \%$ de la población hablante del tseltal, y sobre todo a las mujeres (Inegi, 2004: 64). El grado promedio de escolaridad de la población de 15 años y más hablante de lengua indígena en Chiapas es de 3.2 grados, mientras la media nacional se eleva a 7.5 (Ibid.: 70). 
De acuerdo con cálculos propios basados en datos del Censo de Población y Vivienda 2010 (que no se aplicó en aldeas zapatistas), en la población chiapaneca hablante del tseltal alrededor de 35\% de los 45,800 niños de 0 a 2 años habitan en hogares donde el jefe o la jefa (y/o su cónyuge) solamente habla el idioma maya; es decir, más de un tercio de los niños nacidos en familias de lengua tseltal conviven con al menos una persona adulta que no habla español.

Dado el contexto de guerra de desgaste, analfabetismo y multilingüismo, la aplicación del principio de autodeterminación en educación implica el desarrollo de capacidades de control colectivo y de autogestión en un marco jurídico alternativo que el Estado hoy no reconoce, e incluso desprotege y reprime.

A pesar de ser constitucional y conforme a la Ley General de Educación, la prestación del servicio educativo por instituciones municipales libres no aparece en la agenda política nacional, aunque no haya duda sobre el carácter resolutivamente público del sistema educativo de los cinco Caracoles, los MAREZ y las comunidades autónomas, pues esta alternativa depende de lógicas institucionales propias al "buen gobierno" de cada región.

En los seis años posteriores a su creación, en diciembre de 1994 por el EZLN, casi todos los 38 MAREZ han puesto en práctica su derecho a la autodeterminación educativa sin pedir ni esperar autorizaciones legales u oficiales. $\mathrm{Su}$ resistencia activa en este sector empieza antes del incumplimiento gubernamental de los Acuerdos de San Andrés firmados en 1996, en los cuales aparece de manera explícita e insistente ${ }^{1}$ que "el Estado debe asegurar a los indígenas una educación que respete y aproveche sus saberes, tradiciones y formas de organización" (Hernández y Vera, 1998: 60). Se trataría así de garantizar el derecho a la educación autónoma.

El Estado debe hacer efectivo a los pueblos indígenas su derecho a una educación gratuita y de calidad, así como fomentar la participación de las comunidades y pueblos indígenas para seleccionar, ratificar y remover a sus docentes, tomando en cuenta criterios académicos y de desempeño profesional, previamente convenidos entre los pueblos indígenas y las autoridades correspondientes, y a formar comités de vigilancia de la calidad de la educación en el marco de sus instituciones (Ibid:: 74).

1 Esta misma frase aparece en dos de los tres documentos que constituyen los Acuerdos de San Andrés. Se trata del "Pronunciamiento Conjunto que el Gobierno Federal y el EZLN enviarán a las instancias de Debate y Decisión Nacional" (16 de enero de 1996) y de los "Compromisos para Chiapas del Gobierno del Estado y Federal con el EZLN" (16 de febrero de 1996). 
En el marco de estas negociaciones cruciales para las relaciones entre el Estado nación y los grupos originarios, la propuesta inicial de los asesores e invitados del EZLN, con fecha de noviembre de 1995, instaba a los gobiernos federal y estatales a "restituir y respetar el derecho de las comunidades y pueblos indígenas de seleccionar, ratificar y remover a los maestros, educadores, promotores, instructores y semejantes, de cualquier programa educativo gubernamental y no-gubernamental, sobre la base de criterios y obligaciones acordada entre estos servidores públicos y las propias comunidades en las que laboran" (Ce-Acatl, 1997: 3-4).

En la actualidad, lejos de representar una "ficción jurídica" como lo son muchas reformas constitucionales y legales en este ámbito, estos resolutivos generan políticas locales al ser puestos en práctica de manera unilateral por el conjunto de los pueblos zapatistas, como los que trabajan las tierras "recuperadas” en 1994 en Las Cañadas de Ocosingo (Selva Lacandona) y cuyos representantes se turnan en la Junta de Buen Gobierno con sede en el ejido La Garrucha.

Además, en el espíritu del nuevo federalismo definido en las negociaciones de los acuerdos de San Andrés que según Andrés Aubry (2002) plantea el derecho colectivo a la diferencia, los pueblos tienen la posibilidad de controlar el papel del maestro de escuela ratificando su nombramiento y teniendo el poder de destituirlo de sus funciones. De acuerdo con Elsie Rockwell (1998: 39), esto contribuye a democratizar la educación, gracias a una mayor autonomía.

Con el involucramiento de las familias se busca potencializar el modo de gestión de redes regionales de escuelas en las cuales no es desde el gobierno central donde surgen las decisiones y las prácticas de política educativa, sino desde municipios conformados por comunidades organizadas internamente. En el plano cultural y educativo, la ventaja que se desea obtener de la autonomía regional para los pueblos indios es la de intervenir en la determinación de programas pedagógicos que tendrían que retomar las necesidades específicas, los elementos y valores culturales propios, en un contexto de "verdadera interculturalidad" (Regino, 2004).

Uno de los principales rasgos distintivos de la educación zapatista es el que se construye mediante la acción de un autogobierno indio responsable de crear, organizar, controlar y solventar los procesos locales de la manera que eligen y que estiman más pertinente en relación con una serie de consideraciones de orden social. El retiro de los hijos de las familias rebeldes de las escuelas del "mal gobierno", se hace con base en el principio del derecho a la autodeterminación política. Así, para las familias de los ejidos y ranche- 
rías zapatistas, al solicitar la salida de los maestros e instructores comunitarios remunerados por los gobiernos federal y estatal, se abre la posibilidad de nombrar "compañeros" en asamblea para ocupar cargos de educadores o "promotores de educación autónoma”. ${ }^{2}$

En los comités, concejos, comisiones y asambleas de educación autónoma, las autoridades, las madres, los padres, los ancianos y los jóvenes indígenas zapatistas movilizan recursos humanos, técnicos y materiales en beneficio de sus escuelas, salvo donde la educación se mantiene como informal por la dificultad de autorreclutar y mantener a educadores "en resistencia" frente a los programas gubernamentales, es decir, que no cuentan con ningún apoyo directo del Estado.

El retiro de los niños de las familias rebeldes de las escuelas del "mal gobierno”, entre 1997 y 2000, permite a las bases de apoyo y simpatizantes del EZLN involucrarse plenamente en una experimentación etnoeducativa que parece ser la más amplia entre los pueblos originarios de América. Esto no implica, en cambio, que estos proyectos autogestivos y participativos sean homogéneos y reproducidos de manera idéntica de una región autónoma o Caracol a otro, de un MAREZ a otro o de una comunidad a otra.

La existencia de estos centros educativos dirigidos y animados por las bases de apoyo zapatistas ilustra sobre las formas particulares que adquiere el ejercicio del derecho a la educación en el marco del Convenio núm. 169 de la Organización Internacional del Trabajo (OIT). ${ }^{3}$ Ratificado en 1990 por México, el Convenio precisa que los servicios educativos deberán desarrollarse y aplicarse en cooperación con los pueblos indios, con el fin de responder a sus necesidades específicas (Hernández y Vera, 1998).

Así, se trata de incluir en los programas de enseñanza la historia, los saberes y técnicas de los pueblos, sus sistemas de valores y todas sus aspiraciones sociales, económicas y culturales. Además, el Artículo 14 de la Declaración

2 En la década de 1980, la organización campesina independiente Unión de Uniones impulsó en la Selva Lacandona la conformación de comités de salud y de educación a nivel local, y de comisiones a nivel regional. Asimismo, se extendió el mecanismo del nombramiento comunitario a nuevos puestos de "promotores" que no son profesionales de su área de acción. Los primeros "promotores de educación" (primaria) aparecen en 1988, mientras operaban "promotores de salud" (alópatas) en Las Cañadas de Ocosingo desde varios años antes.

3 El Convenio 169 de la OIT obliga a las autoridades competentes a reconocer las instituciones educativas creadas dentro de límites fijados según consulta previa con los pueblos. Impone al Estado el asegurar la participación en la formulación y ejecución de programas educativos con el fin de transferirles luego estas responsabilidades. 
de las Naciones Unidas sobre los Derechos de los Pueblos Indígenas (13 de septiembre de 2007) reconoce "el derecho a establecer y controlar sus sistemas e instituciones docentes que impartan educación en sus propios idiomas, en consonancia con sus métodos culturales de enseñanza y aprendizaje" (Charters y Stavenhagen, 2010: 408). En el espíritu de este instrumento jurídico internacional, los municipios autónomos ejercen el derecho de instituir y vigilar sus propios sistemas de educación de acuerdo con sus prioridades específicas, formas de organización interna y particularidades socioculturales.

Además, las aportaciones zapatistas a la construcción de un autogobierno educativo se basan en la puesta en práctica de principios de democracia directa ligados a la cultura campesina e indígena, y más precisamente al derecho consuetudinario, cuya normatividad se opone a la del Estado que aún considera estas escuelas como ilegales, mientras son significativamente legítimas según los indígenas.

Este apego al propio acervo cultural explica que una especificidad de los proyectos municipales de escolarización alternativa resida, en gran parte, en la institución del cargo de promotor de educación. Este último es nombrado luego de un proceso de búsqueda de candidatos potenciales, y de la elección y ratificación consensuada en asamblea comunal de la delegación de responsabilidades educativas y de orientación y control de su desempeño.

La libertad educativa permitida por el marco autonómico se sostiene con base en consideraciones que derivan de la autodeterminación político-cultural. En este sentido, la educación autónoma posee una organización propia que no depende de una normatividad impuesta desde afuera, pero que posibilita desde adentro la transmisión social de conocimientos surgidos de prioridades establecidas en colectivo. ${ }^{4}$

Sin embargo, el funcionamiento de las escuelas zapatistas tiende a depender de la amplitud limitada de los márgenes de maniobra política y de los recursos comunitarios disponibles. Cuando el filósofo Cornelius Castoriadis (1975) considera la lucha por la autonomía, es decir, por autoinstituirse, para regirse a partir de reglas propias, la concibe también como una lucha contra la sumisión a instituciones sociales heterónomas que imponen desde el exterior maneras alienantes de pensar y actuar.

De acuerdo con él, la política de la autonomía, por un lado, tiene como objetivo "liberar la creatividad" y "crear la libertad", y por otro, la autonomía

4 Para consultar análisis teóricos más extensos y profundos sobre los contrastes políticos y normativos entre los modelos educativos gubernamentales y zapatistas, véanse Baronnet (2012) y Gómez (2011). 
individual y colectiva también se define como "autolimitación". El objetivo de la autonomía sería, parafraseando a Aristóteles con Castoriadis (1990: 120), hacer de cada individuo un "ser capaz de gobernar y ser gobernado", es decir, fortalecer las capacidades de "mandar obedeciendo" sin pedir permiso al Estado ni recurrir a profesionales de la política.

Situada en el marco del ejercicio de una autonomía política amplia, pero con ciertas limitaciones en términos de recursos, la construcción de sistemas de educación de base, fuera de las modalidades ofrecidas por el Estado, indica que las luchas sociales que las sostienen tienen por objetivo quitar al Estado prerrogativas extensas en materia de política escolar.

En otras palabras, disputan al Estado el derecho de regular, planear y decidir la formación de sus sistemas educativos según sus proyectos político-étnicos. Se oponen abiertamente a la política indigenista centralizada e integracionista que hoy tiene un discurso interculturalista. Antes de evocar más en profundidad la lucha zapatista por una educación "verdadera" que desafía la política nacional de educación llamada "bilingüe intercultural", conviene referirse a las prácticas discursivas y educativas de actores de otros movimientos sociales en regiones multiculturales latinoamericanas, donde el tema sobresaliente de la autonomía educativa antecedió la rebelión armada en Chiapas.

\section{La lucha indígena por la autonomía educativa: una perspectiva latinoamericana}

Desde la perspectiva de los actores de los movimientos indígenas en América Latina, la escuela es a la vez, un derecho, una necesidad, un signo de identidad y parte de un proyecto político, al representar el lugar donde se pueden expresar y articular demandas y necesidades aparentemente contradictorias, como la demanda de autonomía y de integración (Gros, 2000: 190).

Partiendo del análisis de prácticas y de documentos producidos localmente, así como de entrevistas aplicadas entre 2005 y 2007 en la región de las tierras recuperadas de la Selva Lacandona, se puede afirmar que los campesinos indígenas y los ancianos en especial, ven también en la educación un instrumento necesario de desarrollo integral que permite erradicar la "ignorancia”, junto con las discriminaciones que implica en la vida cotidiana. Así, la escuela aparece como un medio para mejorar las condiciones de vida y contribuir a solucionar dificultades sociales (Baronnet, 2012), pero también como un instrumento de formación política y de (re)producción ideológica del movimiento (Gómez, 2011). 
En un contexto en el cual gran parte de los Estados no reconoce en los hechos el derecho de los pueblos originarios y afrodescendientes a crear y desarrollar sus propias instituciones educativas, las experiencias de transformación escolar en marcha contribuyen a demostrar que una política de educación autónoma es posible en la medida en que sus principales actores no asuman directamente las funciones de intermediación corporativa entre la comunidad étnica y el Estado nacional.

En cambio, están interviniendo en el espacio social regional como intermediarios civiles entre la comunidad y la instancia política regional de la que ellos dependen, como los MAREZ en el caso zapatista (Baronnet, 2011). Se puede señalar que una apropiación colectiva y profunda de la escuela no es posible en la medida en que el Estado instrumentaliza el proceso educativo con fines de dominación política, económica y cultural; declarando ilegales y expropiando las iniciativas de política educativa autónoma ligadas al movimiento social.

De cierto modo, la autonomía educativa contribuye a redefinir las relaciones entre los grupos étnicos y el Estado nación. ¿Una nueva relación política del Estado con los territorios de los pueblos originarios y afrodescendientes significaría reconocer la legitimidad social de la acción pública autónoma a nivel local y regional, particularmente en materia de educación, de salud y de producción económica?

En América Latina, hasta la incorporación a finales del año 2007 de la Declaración Internacional de los Derechos Indígenas en la legislación de Bolivia, Nicaragua - con el estatuto de autonomía de la región de la Costa Atlántica - y Colombia - con su fuero indígena - son países que, siguiendo a José del Val (2004: 275), “poseen los desarrollos jurídicos más modernos y completos".

En Nicaragua, en 1987, por medio de la Ley 28, el gobierno sandinista otorgó a las regiones indígenas de la costa Atlántica el derecho de administrar sus asuntos escolares, "mediante programas que recojan su patrimonio histórico, su sistema de valores, las tradiciones y características de su medio ambiente, todo de acuerdo con el sistema educativo nacional". Como resultado de luchas sociales, en Colombia, los avances obtenidos en el derecho etnoeducativo van a la par de cambios en las prácticas político-educativas de los pueblos originarios.

Como organización regional pionera en el escenario de las luchas por los derechos indígenas en América Latina, el Consejo Regional Indígena del Cauca (CRIC) considera a la educación como una prioridad que se concretiza 
en 1978, con la creación en su seno del Programa de Educación Bilingüe, mismo que se consolida en las décadas siguientes. Como antecedente a la experiencia del EZLN en Chiapas, la acción de los comuneros del Cauca descansa en los puntos siguientes:

Que se enseñe en lengua y en castellano. Que se enseñe la cultura y la historia de los indígenas al igual que la historia de los libros. Exigir maestros bilingües pero que conozcan los problemas de los resguardos en donde estén trabajando y orienten a los alumnos sobre los problemas de la comunidad, y que conozcan la cultura, la historia y las luchas de los indígenas y las enseñen a los alumnos (CRIC, 1978: 41).

A la imagen de la lucha del CRIC en los Andes, las movilizaciones y las negociaciones de las nuevas organizaciones indígenas colombianas en los años setenta y ochenta obtienen una legislación más favorable, aunque muy parcialmente implementada. Sin embargo, esto permite abrir en efecto oportunidades de acción colectiva para introducir docentes indígenas en las escuelas de sus territorios.

En 1976 se introduce en la normatividad educativa los temas del consentimiento y de la participación de las comunidades en la selección de maestros y de los contenidos curriculares. Su reglamentación ocurre en 1978, a raíz de acciones políticas del CRIC donde la denuncia, la presión y la protesta se constituyen en mecanismos para obtener el reconocimiento de derechos educativos especiales por medio de negociaciones con el Estado, y establece que el docente "siempre que sea posible" sea "seleccionado por las comunidades indígenas entre los miembros de la misma comunidad" (Castillo y Rojas, 2005: 173).

Este cambio legal permite a los cabildos colombianos organizarse para diseñar y ejecutar sus propuestas curriculares, así como elegir y formar a sus propios maestros. Se institucionalizan luego innovaciones educativas impulsadas por organizaciones indígenas, que salen así de la clandestinidad para competir por la legitimidad y los recursos del Estado. Según Elizabeth Castillo y Axel Rojas (Ibid.: 74), la promulgación de este decreto es un acontecimiento que representa "un referente importante para la configuración de un movimiento pedagógico étnico que desde entonces lucharía constantemente por participar en la formulación de las políticas educativas nacionales".

Con este cambio normativo a su favor, el proyecto educativo del CRIC empieza a concretizarse con las primeras escuelas construidas en tierras tomadas a los grandes propietarios agrarios. Más allá de profesar un discurso crítico hacia el capitalismo, pero tímido sobre las opciones de tipo socialista, las iniciativas educativas del CRIC se inscriben hasta ahora en una dinámica 
de protesta y de adquisición de nuevos derechos, en confrontación con la oligarquía terrateniente (los "usurpadores de nuestras tierras ancestrales"), eclesial (los “curas") y política (los "politiqueros").

Por otra parte, a poca distancia geográfica y cultural de Chiapas, durante la guerra atroz que les opuso al Estado, la lucha de los campesinos mayas desarraigados de Guatemala por su derecho a la educación merece una atención especial, no sólo por formar parte del proyecto político de la resistencia, el refugio y el retorno, sino por el carácter autónomo que su gestión ha adquirido en la cotidianidad.

Después de la firma en 1995 de los Acuerdos de Paz, al imponer a ellos programas y maestros ajenos a su historia y cultura colectiva, la pérdida total de márgenes de autocontrol sobre los asuntos escolares conduce a los ex desplazados y refugiados a buscar y reforzar otros medios de socialización diferentes a la escuela, para permitir la retransmisión de la memoria política, étnica y nacional de los grupos comunitarios. Como bien lo menciona el informe de la Comisión de Esclarecimiento Histórico (1999), "los nuevos elementos de identidad de los desarraigados también iban muy ligados a nuevos principios aprendidos, tales como la defensa de los derechos humanos y civiles, así como una valoración más equitativa del papel de la mujer”.

Así, la preocupación de los mayas por su derecho a aprender a leer, escribir y contar en español sin despreciar su lengua y cultura originaria también forma parte de un proyecto más amplio con perspectivas político-étnicas de cambio social, mediante el autogobierno local.

A pesar de problemas serios de acceso y deserción escolar en los campamentos de refugiados en Chiapas, las nuevas generaciones se encuentran cerca de estar completamente alfabetizadas al emprender con éxito el retorno a Guatemala a mediados de la década de 1990 (Stølen, 2004: 18). De lado de las Comunidades de Población en Resistencia (CPR) en el Quiché, la situación es bastante similar a pesar de condiciones generales mucho menos favorables. En 1994, después de más de una década de organización clandestina, los informes de derechos humanos notan que cuando salen "al claro" no hay pizarrones ni libros, pero que los niños están algo alfabetizados en castellano. ${ }^{5}$

5 En el momento en que estalla el levantamiento zapatista en Chiapas, la Comisión Interamericana de Derechos Humanos (1994: 14) informa en Guatemala de la "existencia de servicios de salud y educación organizados y apoyados por las propias comunidades, tanto en el Ixcán como en la Sierra. [...] Las CPR de la Sierra mantienen un sistema educativo con 18 escuelas (7 en Cabá, 5 en Santa Clara) donde concurren alrededor de 3,500 niños". 
Según el Acuerdo sobre Identidad y Derechos de los pueblos indígenas firmado por el Gobierno de Guatemala y los comandantes guerrilleros en 1995 en la Ciudad de México, el Gobierno se compromete a descentralizar y regionalizar el sistema educativo "a fin de que se adapte a las necesidades y especificidades lingüísticas y culturales”. Aparte de sus objetivos de desarrollar el plurilingüismo e integrar las concepciones educativas mayas a la reforma, el Estado guatemalteco pretende:

Otorgar a las comunidades y a las familias, como fuente de educación, un papel protagónico en la definición de las currícula y del calendario escolar y la capacidad de proponer el nombramiento y remoción de sus maestros a fin de responder a los intereses de las comunidades educativas y culturales; [...] Contratar y capacitar a maestros bilingües y a funcionarios técnicos administrativos indígenas para desarrollar la educación en sus comunidades e institucionalizar mecanismos de consulta y participación con los representantes de comunidades y organizaciones indígenas.

En suma, parece que tanto en Guatemala como en Colombia con el proceso constituyente de 1990-1991, las negociaciones de pacificación son momentos notorios en los que se introduce a la luz pública la cuestión de los derechos de los pueblos indígenas a la autonomía educativa. Sin embargo, en otros países también los cambios normativos tardan en concretizarse, y conviene subrayar que las prácticas de los grupos de indígenas organizados políticamente anteceden a los proyectos de reformas educativas.

En un contexto latinoamericano donde los discursos interculturalistas se vuelven comunes por parte de las ONG y las burocracias educativas, las iniciativas apegadas a los derechos culturales ponen en tela de juicio la política nacional neoindigenista del multiculturalismo neoliberal (Hale, 2007), enseñando que ahora los indígenas políticamente organizados son actores de oposición y de crítica en el debate sobre la reforma educativa, que no sólo debe dirigirse a los pueblos nativos sino a toda la sociedad (Heckt, 2004).

El reto del manejo autónomo de los recursos financieros para la educación de los pueblos indígenas constituye lo que está en juego en las fricciones entre los movimientos indígenas latinoamericanos y los Estados: el reconocimiento de la capacidad y el derecho de crear, organizar y controlar a su conveniencia sus propias instituciones educativas.

Ahora bien, si la autodeterminación en educación implica la democratización de la organización escolar, al mismo tiempo surgen retos jurídicos y prácticos en cuanto al proceso de repudio al modelo indigenista centralista e incapaz de generar procesos que fortalezcan las identidades étnicas, de innovación pedagógica y apropiación del derecho a una escolarización en la 
cual el poder de decisión sobre el quehacer (y el "cómo hacer") educativo sea verdaderamente asumido por los pueblos indígenas.

Una amenaza real a las prácticas novedosas de gestión administrativa y pedagógica de las escuelas manejadas por las autoridades indígenas es la imposición por parte de las instituciones del Estado de formas ideológicas y normativas de concebir y orientar la educación intercultural.

\section{Interculturalismo institucional versus educación "verdadera"}

Por "interculturalismo institucional", Nicanor Rebolledo (2005: 465) identifica la formulación político-cultural contenida en el Programa Nacional de Educación 2001-2006 (PNE), por medio de la cual es esbozada una ideología de la convivencia pacífica entre culturas diferentes, donde su principal reto está planteado en términos de la construcción de una nueva ética pública y en el establecimiento de una educación intercultural para toda la población mexicana, indígena y no indígena. El objetivo de la educación intercultural para todos recuerda lo que advirtió Gonzalo Aguirre Beltrán (1973: 282) en conclusión de una obra clásica:

La educación indígena es aquella que nosotros, los componentes no indígenas de la sociedad mayor impartimos a los grupos de población originalmente americanos; pero, además, es la educación que estamos obligados de proveer a los no indios para ordenar la convivencia que hace posible la formación nacional.

Si bien el PNE no ha generado gran ruptura con la política de educación indígena llevada a cabo en los años noventa, se reconoce desde luego en el papel la imperiosa necesidad de interculturalizar de manera transversal todos los programas escolares nacionales. Si no se logró aún este objetivo de la SEP, aparte de las consideraciones financieras, técnicas y humanas que implica, hay que detenerse sobre el elemento político que lo imposibilitó: la cuestión del derecho a la autonomía política y educativa de las comunidades, municipios y regiones indígenas ausente del Programa Sectorial de Educación 2007 2012 (sEP, 2007).

Aunque la nueva política lingüística y cultural promueva la idea de la interculturalidad para todos, todavía prevalece la no comprensión cabal del concepto y la no preocupación general por entenderlo, habiendo grandes trechos entre el discurso y la acción. En su reflexión sobre "los factores que supone una verdadera educación intercultural bilingüe en un contexto de complejidad histórica, socioeconómica y lingüística de México”, Rebeca Barriga Villanueva (2004: 36-37) sostiene con razón que "el peligro de la intercultu- 
ralidad es que puede disfrazar la unilateralidad y repetir de nuevo el patrón de siempre: una política para indígenas desde el mestizo y no una acción de intercambio equitativo entre culturas y comunidades lingüísticas diversas”.

Al hecho de contar con profesores bilingües de la SEP, con una raquítica formación profesional y poco motivados por el reto interculturalista, se suma la falta de vocación real de educadores y los efectos de su identidad estigmatizada, que conlleva al mantenimiento del proceso de castellanizar y aculturar a sus alumnos "dejando pendiente la tarea de proveer una educación intercultural" (Ramos, 1999: 42). "El requisito de adoptar una identidad étnica positiva se vuelve imprescindible para poder hacer efectivo el proyecto de educación bilingüe e intercultural, alternativa que pretende modificar la historia educativa nacional que han vivido los indígenas desde el siglo xx" (Ibid.).

De acuerdo con Rodolfo Stavenhagen (1996), para que sea verdaderamente intercultural, la educación deberá ser capaz de responder a la vez a los imperativos de la integración planetaria y nacional, y a las necesidades específicas de comunidades concretas, rurales o urbanas, que tienen una cultura propia.

Para que surja una educación realmente pluralista, será necesario replantear los objetivos - ¿qué significa educar y ser educado? -, remodelar los contenidos y los programas de los establecimientos escolares de tipo clásico, imaginar nuevos métodos pedagógicos y nuevos enfoques educativos, y fomentar la aparición de nuevas generaciones de docentes-discentes (Ibid:: 232).

Se trata de basar e inspirar la educación para un mundo multicultural en una filosofía humanista y una ética que - tal como la zapatista - considera positivas las consecuencias sociales del pluralismo cultural. Vista como una alternativa en la construcción de una comunicación educativa más fluida, la interculturalidad se concibe más como una vía adecuada a la realidad social heterogénea, abriendo la posibilidad de enraizar la educación en y a partir de la propia cultura, que promueva un diálogo crítico y creativo entre tradiciones diferentes (Comboni, 2002).

El planteamiento de una verdadera educación intercultural bilingüe radica en la posibilidad y capacidad que tengan los pueblos de construir un nuevo currículum que no exprese únicamente las necesidades de conocimiento y comprensión lingüística de estas poblaciones, sino que se construya en los contextos culturales y exprese en ellos los contenidos sistematizados en una organización pedagógica que permita las comprensiones de los mundos de vida de sus poblaciones, y desde esta construcción logre el diálogo con la cultura universal (Ibid.: 270). 
Sin embargo, es difícil alcanzar este ideal si el proyecto de transformación radical de la escuela monocultural y homogeneizadora no se incluye en un proyecto más amplio de cambio societal. A diferencia de los discursos interculturalistas dominantes, el objetivo central de la educación intercultural indígena es el control sobre las fuerzas de la dominación y el uso egoísta del poder.

Para él, como los conocimientos indígenas se manifiestan de manera permanente en la praxis cotidiana, propone integrar el trabajo escolar a las actividades comunitarias, para que los alumnos participen, actúen, observen, reflexionen e interpreten estas prácticas a partir, a la vez, de las categorías comunes del pueblo y las categorías sociales y científicas de la sociedad nacional. El propósito político de interculturalizar la educación formal responde a intereses estratégicos de política cultural, donde está en juego la cuestión del proceso intersubjetivo de autoafirmación étnica en vínculo con el proceso objetivo de autodeterminación política.

A contracorriente de los discursos interculturalistas dominantes, la educación autónoma de los zapatistas asentados en la principal región de tierras recuperadas en 1994 se reclama "verdadera", es decir, efectiva y coherente con el contexto sociopolítico y los objetivos de los campesinos rebeldes. En palabras del Concejo Municipal Autónomo de Francisco Gómez con sede en el Caracol de La Garrucha, la misión educativa cobra también un sentido político significativo:

Después de que nos levantamos en armas, vimos pues las necesidades de levantar la educación que necesitamos en nuestras propias manos para que como pueblo aprendamos lo que necesitamos, conocer nuestras historias verdaderas de nuestros pueblos que aquí es el tzeltal y conocer el mundo y de nuestros países, y prepararnos con el estudio para la lucha, la construcción de la autonomía y la transformación de nuestro país. Nacimos entonces la educación autónoma que le llamamos slecubtesel lumaltic que es mejorando nuestros pueblos, donde nuestros pueblos en resistencia tiene el promotor que es de su comunidad para que sea según vemos pues que así nos fortalecemos como pueblos y en organización tenemos el plan de construir un centro de capacitación del Municipio Autónomo Francisco Gómez pensamos que el centro debe de tener la capacidad de recibir 300 promotores de distintas comunidades (transcripción del "Comunicado a las sociedades civiles”, MAREz Francisco Gómez, 23 de octubre de 2006).

En el testimonio siguiente, un joven promotor de educación originario del nuevo centro de población Patria Nueva, en tierras recuperadas de la ex finca El Recreo, pone de manifiesto que su tarea educadora descansa en la reapropiación en el aula de conocimientos campesinos y étnicos locales, de acuerdo con valores colectivos compartidos en la educación "verdadera": 
Dentro de nuestra educación autónoma, no es como la oficial donde se les da becas a los niños para que piensen como el gobierno dice. De nosotros, es el pueblo que manda, por eso se respeta la lengua de cada comunidad. Nuestra educación viene de nuestra palabra, es nuestro conocimiento, porque siempre nace de la comunidad, porque los promotores somos los compañeros que les ayudamos a los niños. De lo que sabe uno pues lo comparte con otros, vamos a aprender juntos, paso a paso pero parejo todo, por eso digo que hay que sacar la experiencia, investigar el pueblo, eso es lo que hacemos en nuestra escuelita, damos a conocer lo que no sabe el pueblo para mejorar. Sí, mejorar al pueblo, porque de por sí hay mucha necesidad, por eso hay que darles a conocer bien a los niños por qué estamos luchando, lo que es la lucha zapatista, lo que es el compañerismo, lo que es la injusticia (entrevista, MAREz Francisco Villa, agosto de 2005).

Los valores sociales contenidos en los principios pedagógicos enunciados por este "maestro-campesino" zapatista remiten a la búsqueda de cierta horizontalidad en la relación entre el educador y el alumno. Esta transformación constituye "un paso ineludible para descolonizar el proceso de producción de conocimiento en la escuela, lo cual implica la aceptación mutua de saberes aprendidos que es fundamental contrastar e implica que los nuevos saberes que surjan vayan definiéndose y redefiniéndose en un proceso que es histórico y legítimo" (Maris y Solari, 2009: 189).

La legitimidad social de la figura del educador zapatista y de los saberes que valora en la escuela se alimenta en gran medida del origen comunitario y militante de jóvenes campesinos, quienes son bilingües y a veces trilingües (lenguas mayas y "castilla"). Aprovechando el arraigo local del docente para extender el acceso a la escuela, el proceso de nombramiento comunitario del promotor de educación autónoma ocurre con un modo bastante similar a la designación de las autoridades mayas en los cargos políticos y religiosos de los "servidores del pueblo" (Lomelí, 2002).

A escala comunitaria y regional, el ejercicio autonómico implica entonces la redefinición de la posición social del docente en el campo político y educativo tanto a nivel organizativo como pedagógico, a través de una participación directa por medio de asambleas locales y regionales que delinean los objetivos y los criterios pedagógicos. Por ejemplo, en el MAREz Ricardo Flores Magón, desde el año 2000, según el Concejo Municipal Autónomo renovado cada tres años, se halla una serie de:

[...] intervenciones directas de los pueblos y autoridades para las tomas de decisiones, programas, calendarios y sus formas para las capacitaciones, para nosotros son muchos los avances que hemos realizado y de las que siguen en proceso dentro del municipio para crecer una educación autónoma y verdadera para nuestros pueblos que ayude a lograr la vida digna y fortalecer su cultura y que les abra horizontes de acuerdo a su 
realidad regional (transcripción del "Comunicado a las sociedades civiles", MAREz Ricardo Flores Magón, 10 de octubre de 2006).

$\mathrm{Al}$ apropiarse del control de sus escuelas, las asambleas de los zapatistas redefinen las prioridades, las necesidades y la calidad que exigen del sistema alternativo que sostienen desde hace alrededor una década en la zona Selva Tseltal. Además, al desafiar los resultados de las medidas tomadas por el poder educativo nacional, este proceso de resistencia política contribuye a afianzar y reafirmar las conciencias subjetivas de pertenecer a un grupo socioétnico y político determinado.

Más que un reto utópico, el sentido emancipador que otorgan las familias zapatistas a su proyecto político de transformación social y educativa parece inscribirse en una lógica de redefinición desde abajo de lo que se espera de la escuela comunitaria; lo cual contribuye al final a reafirmar por medio de ella los atributos identitarios de los grupos considerados.

\section{La apuesta: descolonizar la educación de los pueblos originarios}

A pesar de las consecuencias de la guerra integral de desgaste y las condiciones de pobreza material, desde finales de los años noventa, los campesinos mayas y zapatistas de Las Cañadas de la Selva Lacandona, de los Altos y el Norte de Chiapas construyen prácticas educativas renovadas al seno de proyectos radicales de autonomía política. A nivel comunitario y municipal, las familias indígenas y sus representantes adquieren compromisos y responsabilidades en la gestión administrativa y pedagógica de las escuelas primarias. En cierta medida, esto les permite controlar, desde la esfera política local, los criterios de orientación y de evaluación de lo que es culturalmente pertinente enseñar y estudiar.

De acuerdo con el campesino responsable de vigilar el funcionamiento de una nueva escuela ubicada en el antiguo casco de la finca El Paraíso, "la educación es como una matita de maíz, si no la cuidas se muere”. Este experimentado militante zapatista que funge como "comité de educación" de la escuela Ernesto "Che" Guevara del poblado Nuevo Paraíso agrega que "el trabajo de la educación autónoma necesita atención y también todo el apoyo del pueblo para que haiga avance" (entrevista personal, MAREz Francisco Villa, octubre de 2005).

Las palabras de un joven padre de familia de la ranchería Zapata ilustran también la relación de solidaridad e interdependencia entre las bases de apoyo zapatistas y su propio educador, quien además se destaca como poeta y maestro de ceremonia: 
[...] a nuestro promotor lo estamos orientando para que saque adelante a la educación. Sin el pueblo que oriente, no hay educación; lo estamos diciendo por dónde hay que caminar, por ejemplo, le decimos que hay que luchar para mejorar el aula, que hay que enseñar la verdad de cómo son las cosas, de cómo es nuestros costumbres, nuestros derechos, de cómo es lucha de la organización y de las otras organizaciones que luchan por la tierra (entrevista, MAREZ Francisco Villa, enero de 2007).

Como consecuencia del pragmatismo de los promotores y las autoridades zapatistas, las prácticas pedagógicas observables en las comunidades rebeldes son muy eclécticas, sin que se pueda hablar tampoco de realidades educativas contradictorias y descontextualizadas. En efecto, la autonomía política favorece la redefinición colectiva y permanente de las prioridades y necesidades educativas, así como los criterios de evaluación de la calidad y pertinencia de la enseñanza puesta bajo control local. De manera pragmática y a veces improvisada, se trata así de poner en práctica las consignas infundidas por el movimiento zapatista de forma interna:

Compañeros y compañeras, para alcanzar la educación que necesitamos los pobres, debemos seguir luchando para que haya mejor educación, pero es mejor empezar desde ahora la educación del pueblo, por eso es necesario entender que debemos empezar a preparar a nuestros niños y jóvenes, y preparar nuestros planes y programas de educación por el pueblo en los diferentes niveles de educación, de acuerdo a nuestros ideales y nuestros intereses como pueblo (transcripción del programa "Demanda Educación" de Radio Insurgente, MAREz Francisco Gómez, 10 de junio de 2005).

Partiendo de una estrategia liberadora que forma parte de una política cultural construida "desde abajo", los pueblos organizados en los MAREZ plantean la autonomía educativa como vía para (re)valorizar los conocimientos generales, prácticos y éticos que estiman útiles, prioritarios y pertinentes para vigorizar su identidad y afianzar su dignidad al ser miembros de un pueblo tseltal y mexicano, de familia campesina y activos zapatistas en la comunidad y la región. Según Rodolfo Stavenhagen (2006: 221), los pueblos oprimidos, explotados y discriminados que reclaman sus derechos culturales y colectivos lo hacen para garantizar sus derechos humanos y para lograr un mínimo de poder en la polis que les permita participar en condiciones de igualdad en la gobernanza democrática de sus países.

Las experiencias de autonomía educativa ilustran la capacidad del movimiento político y cultural zapatista de apropiarse de manera innovadora el derecho de los indígenas a una autonomía educativa, de acuerdo con sus propias estrategias sociales. Se trata de un modo alternativo de integración a "un mundo en el cual quepan todos los mundos", según la famosa fórmula del 
EZLN, pues la cuestión ideologizada del multiculturalismo tiene que ver con proyectos divergentes de nación (Ibid.).

$\mathrm{Al}$ acceder a la modernidad por diversos espacios - como el mercado, pero sobre todo la escuela-, los indígenas han podido tomar conciencia de su posición social y constituirse en sujetos que encuentran en esa modernidad (económica, jurídica, educativa, etc.) los medios para criticarla y defender su identidad y sus derechos (Gros, 2001: 59-60). Sin embargo, los esfuerzos por imaginar escuelas bilingües e interculturales disponiendo de mayores márgenes de maniobra provienen hasta ahora más de las organizaciones indígenas y de sus apoyos (Iglesias, ONG, etc.) que de los Estados y las clases dominantes (Ibid.: 69), los cuales los niegan y reprimen.

Las políticas públicas enfocadas en la educación rural en contexto multicultural encuentran sus límites cuando la represión estatal contra las iniciativas de autonomía educativa impide que se movilicen las comunidades como sujetos capaces de deliberar y decidir sobre la organización escolar, la docencia y los cambios por aportar a su funcionamiento cotidiano.

Para algunos políticos e intelectuales de izquierda agrupados en el Movimiento Indígena Nacional (cercano al Partido de la Revolución Democrática), es necesario que el Estado reconozca la competencia de los pueblos como sujetos de derecho en las regiones autónomas, para elaborar en coordinación con cada gobierno local los planes y programas de estudio, y vigilar la labor docente. No obstante, la política oficial de educación indígena en los últimos sexenios no viene encabezada por los sujetos colectivos, es decir, los pueblos originarios, para participar en la toma de decisión, la aplicación y la evaluación de la política social, la cual representa un reto para gobernar en la diversidad cultural.

Por su lado, desde su creación en 1996 por el movimiento zapatista, el Congreso Nacional Indígena (CNI) reivindica el derecho de establecer planes y programas regionales de desarrollo socioeconómico y educativo con participación de las comunidades, así como elaborar, someter a consenso y ejecutar políticas públicas en su jurisdicción. Las posturas políticas de las diversas organizaciones indígenas en México parecen concordar con los Acuerdos de San Andrés defendidos por el CNI en materia educativa (López, 2005).

En efecto, la autonomía educativa surge, desde luego, como una de las demandas centrales del movimiento indígena en su búsqueda por emanciparse de la política educativa impuesta por actores ajenos a la realidad comunitaria en el escenario escolar local. Sin embargo, en los encuentros públicos de las organizaciones de autoridades indígenas en México, aún son poco visibles 
las innovaciones experimentadas en los proyectos regionales alternativos de educación formal y extraescolar.

$\mathrm{Al}$ estar sostenidas y orientadas en las experiencias y demandas de las comunidades organizadas, las políticas municipales de educación zapatista cuestionan el multiculturalismo neoliberal de las políticas educativas de corte neoindigenista que niegan los procesos de autonomía de facto y reprimen los intentos de poner en práctica los derechos colectivos (Hernández et al., 2004).

A partir de un ejercicio democrático y participativo, las comunidades organizadas buscan resolver por sí mismas las carencias que prevalecen en términos de derechos educativos, entendiendo éstas en los términos de Katarina Tomaševski (2006) como la falta de disponibilidad, accesibilidad, aceptabilidad y adaptabilidad de las ofertas educativas a niños, niñas, jóvenes y personas adultas. La gestión autónoma y participativa de las escuelas representa así una manera colectiva de facilitar que éstas se encuentren disponibles, accesibles, aceptables y adaptables para las particularidades de la sociedad multicultural, a nivel rural como urbano.

La práctica de la autogestión de las escuelas conlleva en toda lógica a garantizar fundamentalmente que se tomen en cuenta las especificidades identitarias y organizativas locales a la hora de definir el quehacer educativo. De cierta manera, la principal ventaja que los pueblos zapatistas consideran acerca de la autonomía escolar es su capacidad de (re)valorizar los saberes generales, prácticos y éticos, que estiman útiles, necesarios o prioritarios para fortalecer su identidad y su dignidad al ser miembros -o sujetos- de un pueblo tseltal; como mexicanos, de familias campesinas pobres y activos militantes zapatistas.

Desde la perspectiva de los pueblos zapatistas, los sistemas municipales de escuelas autónomas son legítimos (aun cuando no tengan reconocimiento legal) porque responden al proyecto político y cultural al cual se adhieren las comunidades. Sin embargo, en los procesos cotidianos de consulta y movilización del sector educativo zapatista se ha observado que algunos campesinos tseltales han ido perdiendo el interés o el compromiso (por "el cansancio") en los asuntos de política educativa local.

Considerando la necesidad de participación incluyente en la que confluyen las lógicas de organización comunitaria (usos y costumbres) y las organizaciones de la comunidad (militancias políticas regionales), esto puede poner en peligro la continuidad y el desarrollo local de la oferta comunitaria de educación "verdadera". 
La autonomía educativa en aquellos territorios en los que "manda el pueblo" tiende a ser una solución endógena y flexible para enfrentar la contradicción representada por la importancia de escolarizar a los niños indígenas y, simultáneamente, evitar la intervención de actores educativos ajenos a la comunidad y a su cultura. El compromiso colectivo de conformar sus propios sistemas de educación en condiciones complejas se ha plasmado en la consistente construcción de redes escolares municipales.

En ellas y a través de la participación comunitaria en los asuntos educativos, se han reconfigurado la misión y la posición social del docente. Para los campesinos indígenas zapatistas de Chiapas, la educación "nace" de la comunidad; lo cual no significa que la escuela de los "autónomos" sea cerrada, sino que realiza una articulación pragmática entre los conocimientos localmente situados y los que provienen de la cultura escolar dominante a nivel nacional (Baronnet, 2012; Gómez, 2011).

Declarándose en rebeldía, en resistencia y autónomos frente al Estado, los MAREZ, desde hace más de una década, "levantan la educación del pueblo" para "salir de la ignorancia”. La capacidad de deliberación y de acción soberana supone entonces la organización de los sujetos de modo independiente de las estructuras estatales dominantes, contando con la vocación real, la voluntad de participación activa y plena de los miembros del colectivo potencialmente habilitado para tomar una decisión que lo afecte (Thwaites, 2011). Los pueblos zapatistas, al perseguir la autogestión comunitaria de proyectos escolares regionales, apuestan al ideal revolucionario que consiste en descolonizar la cultura escolar de corte neoindigenista, la cual, con sus métodos, planes y programas, es discriminatoria hacia las culturas indígenas.

\section{Conclusiones}

Cada municipio zapatista está concretando, de forma particular y creativa, el proyecto democratizador autonómico a pesar de diversas dificultades y muchos obstáculos ligados al contexto y a recursos limitados. A partir de procesos asamblearios y de sus propios mecanismos y recursos económicos, sociales, culturales y políticos, cada escuela presenta su singularidad organizativa y pedagógica, aunque a veces no estén escritos los temarios y los planes y programas de estudio.

No obstante, estando "en resistencia" frente al Estado, las prácticas autonómicas comparten elementos comunes que aparecen en oposición a la política educativa nacional. Buscan no depender de un poder centralizado a nivel 
organizativo, estatal y nacional, basándose en los actores comunitarios y sus representantes directos que orientan, vigilan y evalúan tanto el compromiso político como el rol pedagógico del docente.

Lejos de ser la aplicación mecánica de un modelo rígido y uniforme impuesto por el EZLN a sus bases de apoyo, la autonomía educativa radical ha generado procesos sociales de apropiación y reinvención desde abajo de la institución escolar a partir de las estrategias de los campesinos mayas zapatistas. Como elementos constitutivos de luchas por la dignidad, las prácticas de política educativa de los pueblos organizados en los MAREZ demuestran que no es utópico aspirar a administrar, de manera autogestiva, escuelas rurales insertas en redes regionales con el respaldo de una organización política movilizadora como el EZLN.

La práctica de la autonomía desafía al Estado para que transforme su política educativa basándola en los valores y las prioridades decididas por los pueblos indígenas según sus modos particulares de gobernarse. Pese a esto, las condiciones políticas aún no están reunidas para que los pueblos zapatistas se beneficien de la contraparte financiera y técnica que pueden otorgar las administraciones públicas de nivel estatal y federal. Dada la diversificación de las modalidades educativas de educación básica oficial que ocurrió en las Cañadas en los años noventa, las crecientes desigualdades y rivalidades inter e intracomunitarias se agudizan con la puesta en competencia constante de subsistemas de escuelas que se distinguen por el origen social y la formación del docente, y también por los salarios y equipamientos asignados (Baronnet, 2012).

En la autonomía zapatista, la escuela en su conjunto es adaptada, o mejor dicho, readaptada a nivel comunitario gracias a una evolución permanente de la tradición y de la movilización de los esfuerzos colectivos, que hacen posible la apropiación social del espacio escolar y del tiempo consagrado a la escolarización.

A contracorriente del multiculturalismo neoliberal, los aportes zapatistas a la construcción de la autonomía educativa se basan en los principios de democracia directa ligados a la cultura campesina e indígena. Más precisamente al derecho consuetudinario, donde la norma local se opone a la del Estado que considera hasta ahora a las escuelas autónomas como ilegales, aunque sean legítimas desde el punto de vista de los actores que las construyen.

Documentar en profundidad y sistematizar las prácticas de educación propia, autónoma y en resistencia puede contribuir a comprender mejor ésta y otras lecciones de las experiencias de administración de los pueblos 
indígenas de Latinoamérica. Mismas que merecen mucha atención, tanto por parte de la sociedad como de los gobiernos locales, regionales y nacionales, en la medida en que sirven para impedir que el derecho al conocimiento contradiga al derecho a la identidad. Demuestran que la construcción de la autonomía indígena en distintos contextos, es un proceso sociológico complejo, históricamente instituido. Ésta contribuye, en cierta medida, a facilitar la apropiación social de la escuela como espacio de participación comunitaria en el quehacer político, administrativo y pedagógico.

Esta reflexión conduce a comprender mejor el complejo proceso de construcción social de la demanda indígena de autonomía educativa que, con el impulso del EZLN desde hace cerca de dos décadas, se ha concretado en las prácticas colectivas, bajo la forma de una apropiación sui generis del derecho de los pueblos a establecer y administrar sus instituciones educativas según sus propias metas y formas de organización y de decisión. La realidad zapatista muestra la actualidad del pensamiento de Castoriadis (1990: 170), cuando establece que se puede desarrollar la autonomía sólo con su ejercicio efectivo, al crear instituciones que posibilitan el acceso a la autonomía individual y a la participación colectiva a todo poder explícito que existe en la sociedad.

\section{Bibliografía}

Aguirre Beltrán, Gonzalo (1973), Teoría y práctica de la educación indígena, México: Secretaría de Educación Pública.

Aubry, Andrés (2002), "La autonomía en los acuerdos de San Andrés: expresión y ejercicio de un nuevo pacto federal", en Mattiace, Shannan et al. [eds.], Tierra, libertad y autonomia: impactos regionales del zapatismo en Chiapas, México: CIESAS, IWGIA.

Baronnet, Bruno (2011), "Entre el cargo comunitario y la militancia zapatista: los promotores de educación de la zona Selva Tseltal", en Bruno Baronnet, Mariana Mora y Richard Stahler-Sholk [coords.], Luchas "muy otras". Zapatismo y autonomia en las comunidades indigenas de Chiapas, México: UAM-Xochimilco, CIESAS, UNACH.

Baronnet, Bruno (2012), Autonomía y educación indigena. Las escuelas zapatistas de la Selva Lacandona de Chiapas, México, Quito: Abya-Yala.

Barriga Villanueva, Rebeca (2004), "La interculturalidad en tres preguntas", en Corona Berkin, Sarah y Barriga Villanueva, Rebeca [coords.], Educación indigena: en torno a la interculturalidad, Guadalajara: Universidad de Guadalajara, Universidad Autónoma Metropolitana.

Castillo, Elizabeth y Axel Rojas (2005), Educar a los Otros. Estado, politicas educativas y diferencia cultural en Colombia, Popayán: Universidad del Cauca.

Castoriadis, Cornelius (1975), L'institution imaginaire de la société, París: Seuil.

Castoriadis, Cornelius (1990), Le monde morcelé. Les carrefours du labyrinthe III, París: Seuil. 
Ce-Acatl (1997), "Diálogo de Sacamch'en. Mesa de trabajo 1: Derechos y Cultura Indígena”, en Revista Ce-Acátl, núm. 74-75, México: Centro de Estudios Antropológicos, Científicos, Artísticos, Tradicionales y Lingüísticos A.C.

Charters, Claire y Rodolfo Stavenhagen [eds.] (2010), El desafío de la Declaración. Historia y futuro de la declaración de la ONU sobre Pueblos Indigenas, Copenhague: IWGIA.

Comboni, Sonia (2002), “Interculturalidad, educación y política en América Latina”, en Política y Cultura, núm. 7, México: Universidad Autónoma Metropolitana.

Comisión de Esclarecimiento Histórico (1999), Guatemala: Memoria del Silencio, Guatemala: UNOPS.

$\mathrm{CIDH}$ (Comisión Interamericana de Derechos Humanos) (1994), Informe especial sobre la situación de los derechos humanos de las llamadas "Comunidades de Población en Resistencia” de Guatemala, Washington: CIDH, Organización de los Estados Americanos.

CRIC (Consejo Regional Indígena del Cauca) (1978), Diez años de lucha. Historia y Documentos, Bogotá: CINEP, Editorial Guadalupe, CRIC.

Gómez Lara, Horacio (2011), Indígenas, mexicanos y rebeldes: procesos educativos y resignificación de identidades en los Altos de Chiapas, México: Juan Pablos, UNICACH.

Gros, Christian (2000), Políticas de la etnicidad: identidad, Estado y modernidad, Bogotá: ICANH.

Gros, Christian (2001), “Le multiculturalisme à l'école : entre mythe et utopie”, en Recherches Amérindiennes au Québec, vol. 31, núm. 3, Montreal: RAQ.

Hale, Charles (2007), "Más que un indio". Ambivalencia racial y multiculturalismo neoliberal en Guatemala, Guatemala: AVANCso.

Heckt, Meike (2004), Guatemala: pluralidad, educación y relaciones de poder: educación intercultural en una sociedad étnicamente dividida, Guatemala: AVANCSO.

Hernández Castillo, Aída, Teresa Sierra y Sarela Paz [coords.] (2004), El Estado y los indigenas en tiempos del PAN: neoindigenismo, legalidad e identidad, México: CIESAS, Miguel Ángel Porrúa.

Hernández Navarro, Luis y Ramón Vera Herrera [comps.] (1998), Acuerdos de San Andrés, México: Era.

Instituto Nacional de Estadística, Geografía e Informática (Inegi) (2004), La población indígena en México, México: Inegi.

Lomelí, Arturo (2002), Los servidores de nuestros pueblos. Syu'el jtuuneletik ta jlumaltik, Tuxtla Gutiérrez: Coneculta.

López Bárcenas, Francisco (2005), Autonomia y derechos indigenas en México, México: UNAM.

Maris García, Stella y Verónica Solari Paz (2009), "Investigar la escuela: desafíos desde la antropología”, en Tamagno, Liliana [coord.], Pueblos indigenas: interculturalidad, colonialidad, politica, Buenos Aires: Biblos.

Ramos Ramírez, José Luis (1999), “El drama de llegar a ser maestro indígena”, en Sinéctica, núm. 15, Guadalajara: ITEso. 
Rebolledo, Nicanor (2005), "Interculturalismo y autonomía. Reflexiones en torno al movimiento indígena y a las políticas educativas", en Anuario Educativo Mexicano 2004, México: UPN Ajusco.

Regino, Adelfo (2004), “Diversidad y autonomía. Un aporte desde la experiencia indígena mexicana”, en Renglones, núm. 56, Guadalajara: ITESO.

Rockwell, Elsie (1998), “Democratización de la educación y autonomía: dimensiones históricas y debates actuales”, en El Cotidiano, núm. 87, México: UAM.

Secretaría de Educación Pública (SEP) (2007), Programa sectorial de educación 2007-2012, México: SEP.

Stavenhagen, Rodolfo (1996), "Education for a multicultural world”, en Delors, Jacques [coord.], Learning: The Treasure Within, Report to UNESCO of the International Commission on Education for the Twenty-first Century, París: Unesco.

Stavenhagen, Rodolfo (2006), "La presión desde abajo: derechos humanos y multiculturalismo", en Daniel Gutiérrez [comp.], Multiculturalismo: desafíos y perspectivas, México: Siglo XXI, unam, El Colegio de México.

Stølen, Kristi Anne (2004), "The Reconstruction of Community and Identity among Guatemalan Returnees”, en Revista Europea de Estudios Latinoamericanos y del Caribe, núm. 77, Amsterdam: CEDLA.

Thwaites Rey, Mabel (2011), “La autonomía: entre el mito y la potencia emancipadora”, en Modonesi, Massimo et al., Pensar las autonomias. Alternativas de emancipación al capital y el Estado, México: Sísifo Ediciones.

Tomaševski, Katarina (2006), Human Rights Obligations in Education. The 4-A Scheme, Nijmegen: Wolf Legal Publishers.

Val, José del (2004), México nación multicultural, México: PUMC-UNAM.

\section{Entrevistas y otros documentos citados}

Programa "Demanda Educación" de Radio Insurgente, 10 de junio de 2005, MAREZ Francisco Gómez.

Gregorio, promotor de educación autónoma, Patria Nueva, entrevista grupal realizada en San Marcos, Marez Francisco Villa, agosto de 2005.

Alejandro, Comité de Educación Autónoma, escuela Ernesto "Che" Guevara, Nuevo Paraíso, entrevista personal, MAREz Francisco Villa, octubre de 2005.

Concejo Municipal Autónomo "Ricardo Flores Magón”, Comunicado a las sociedades civiles, ejido La Culebra, 10 de octubre de 2006.

Concejo Municipal Autónomo "Francisco Gómez", Comunicado a las sociedades civiles, ejido La Garrucha, 23 de octubre de 2006.

Sebastián, padre de familia, ranchería Emiliano Zapata, entrevista personal, MAREZ Francisco Villa, enero de 2007. 
Bruno Baronnet. Profesor e investigador (SNI 1) en Ciencias Sociales adscrito al Instituto de Investigaciones en Educación de la Universidad Veracruzana (Xalapa). Es investigador asociado al Laboratorio de Antropología de las Instituciones y Organizaciones Sociales (LAIOS-EHESs, Francia). Tiene un doctorado en Sociología por El Colegio de México y la Universidad de París (2009). Líneas de investigación: socio-antropología de la educación de los pueblos originarios en México y Latinoamérica: políticas públicas, prácticas de autonomía indígena y educación intercultural; movimientos sociales, estrategias educativas y escuelas alternativas en territorios multiculturales; educación popular, niñez y juventud en el medio rural. Publicaciones recientes: "Lenguas y participación comunitaria en la educación indígena en México", en Revista de Antropología Iberoamericana, vol. 8, núm. 2, mayo/agosto, Madrid: AIBR (2013); "L'expérience d'éducation zapatiste au Chiapas: entre pratiques politiques et imaginaires autochtones à l'école”, en Cabiers de la recherche sur l'éducation et les savoirs, núm. 12, París: ARES (2013); "Racismo y discriminaciones en el sistema educativo mexicano", en Gabriel Ascencio [coord.], Teoría y práctica de la educación intercultural en Chiapas, México: UnAm (2013).

Recepción: 31 de enero de 2013.

Aprobación: 14 de julio de 2014. 